\title{
Persistent transmission of malaria in Garo hills of Meghalaya bordering Bangladesh, north-east India
}

\author{
Vas Dev ${ }^{1 *}$, Barlind M Sangma², Aditya P Dash ${ }^{3}$
}

\begin{abstract}
Background: Malaria is endemic in Garo hills of Meghalaya, and death cases are reported annually. Plasmodium falciparum is the major parasite, and is solely responsible for each malaria-attributable death case. Garo hills are categorized high-risk for drug-resistant malaria; however, there exists no data on malaria transmitting mosquitoes prevalent in the region. Included in this report are entomological observations with particular reference to vector biology characteristics for devising situation specific intervention strategies for disease transmission reduction.

Methods: The epidemiological data of the West Garo hills have been reviewed retrospectively for 2001-2009 to ascertain the disease transmission profile given the existing interventions. Point prevalence study was conducted in Dalu Community Health Centre that lies in close proximity to international border with Bangladesh to ascertain the true prevalence of malaria, and parasite species. Mosquito collections were made in human dwellings of malaria endemic villages aiming at vector incrimination, and to study relative abundance, resting and feeding preferences, and their present susceptibility status to DDT.

Results: Investigations revealed that the West Garo hill district is co-endemic for Plasmodium falciparum and Plasmodium vivax, but P. falciparum was the predominant infection (> 82\%). Malaria transmission was perennial and persistent with seasonal peak during May-July corresponding to months of high rainfall. Entomological collections revealed that Anopheles minimus was the predominant species that was incriminated by detection of sporozoites in salivary glands (infection rate 2.27\%), and was ascertained to be fully susceptible to DDT.

Conclusion: For the control of malaria, improved diagnosis and sustained supply of drugs for artemisinin-based combination therapy are strongly advocated, which should be enforced for treatment of every single case of $P$. falciparum. Greater political commitment is called for organized vector control operations along border/high-risk areas to contain the spread of drug-resistant malaria, and averting impending disease outbreaks.
\end{abstract}

\section{Background}

Malaria is major public health concern in the north-eastern states of India that continues to deter the equitable socio-economic development of the region [1]. Among seven sister states of north-east India, much of the research investigations related to malaria epidemiology and control were reported from Assam [2]. Of its adjoining states which are just as malaria endemic, Meghalaya $\left(25^{\circ}-26^{\circ} \mathrm{N}\right.$ latitude \& $90^{\circ}-93^{\circ} \mathrm{E}$ longitude) contribute $>20 \%$ of cases of those reported from the north-east

\footnotetext{
* Correspondence: mrcassam@hotmail.com

${ }^{1}$ National Institute of Malaria Research (Field Station), Chachal, Guwahati

781 022, Assam, India

Full list of author information is available at the end of the article
}

states annually [3]. Despite full logistics support and increased allocation of resources from centrally funded schemes of National Vector Borne Disease Vector Control Programme (NVBDCP), case incidences are on the rise with attributable death reports associated with focal disease outbreaks that are visiting annually affecting bordering population groups. There exists little data on abundance, infectivity, and feeding behaviour of malaria transmitting mosquito vector species, and to their present susceptibility status to DDT, the commonly used residual insecticide for vector control. Among all districts of Meghalaya that are malaria endemic, the Garo hills persistently contribute the majority of Plasmodium falciparum cases $(>60 \%)$ and attributable deaths, and the 
district is categorized high-risk for drug-resistant malaria (source, state health directorate). In understanding the local disease epidemiology for disease prevention and containment, the objectives of the present study were to review the malaria situation retrospectively for the years between 2001 - 2009 under present disease surveillance, and report entomological observations with particular reference to vector biology characteristics for devising situation specific intervention strategies for disease transmission reduction. The study had the approval of the institutional ethics committee.

\section{Methods}

\section{Study area}

The investigations were focused in the West Garo Hill district that is prone to focal disease outbreaks characterized by an increase in P. falciparum cases and associated deaths ascribed to multi-drug resistant malaria. The district is mostly hilly bounded by interstate border with Assam to the North, and international border with Bangladesh to the South (Figure 1). The terrain is difficult, population is sparse, and tribal aborigines are the majority ethnic population (> 70\%), living in rural areas and practicing shifting paddy cultivation for subsistence. It rains heavily during May to September, and the total rainfall varies from 2.5 - 4.5 meters annually. During these months, many of the foothill villages are affected by waves of flash floods limiting access to healthcare services. For most of the year, average temperatures $\left(23-28^{\circ} \mathrm{C}\right)$ and relative humidity $(>70 \%)$ are conducive for mosquito breeding and longevity permitting perennial transmission.

\section{Disease surveillance and control interventions}

In West Garo Hill district, there are 24 Primary Health Centers/Community Health Centers each of which has diagnostic and treatment facilities for malaria that serve as reporting centre for malaria incidence under NVBDCP. The data on malaria incidences from all sources, i.e., active fever surveillance based on fortnightly domiciliary visits, passive case detection (malaria clinic), and mass and contact surveys were pooled monthly/annually. For vector control interventions, annual two rounds of residual spraying of DDT @ 1 gm per square meter were conducted in areas reporting high incidence of P. falciparum cases and attributable deaths, of which first round was usually conducted during March - May, and second beginning July to be completed by end of September each year. Other measures included provision for focal spraying (in areas reporting disease outbreaks characterized by high rise in case incidences), impregnation of community-owned mosquito nets, and supply of mosquito net gratis in below poverty population groups. In addition, programmes of health education and awareness for self-protection supported by media and non-governmental organizations were routinely conducted particularly during months of

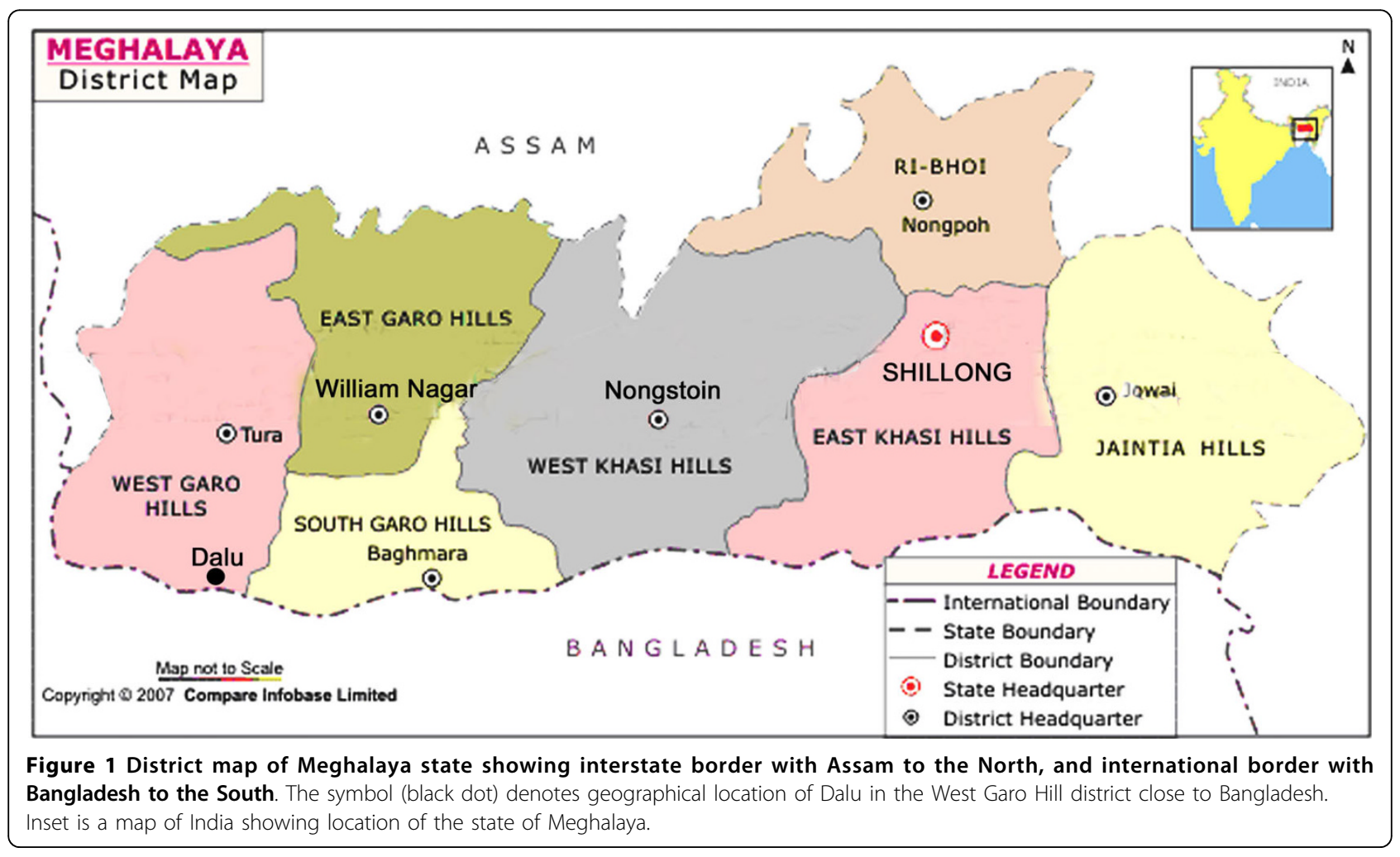


high transmission period. The anti-parasite measures included chemotherapy for every single confirmed cases of malaria by anti-malarial drug policy in force that was subject to revision periodically. Chloroquine was the drug of choice up until 2004, when it was replaced by sulphadoxine-pyrimethamine, and beginning 2007, it was changed over to combination therapy (artesunate + sulphadoxinepyrimethamine) for treatment of $P$. falciparum cases. Re-orientation and training programmes for health personnel are conducted annually as capacity building exercises for strengthening healthcare services particularly in high-risk areas.

\section{Entomological techniques}

Although malaria cases are reported across the district, there is greater concentration of cases in foothill villages that lie close to inter-state/inter-country borders. Thus, to ascertain the prevalent anopheline mosquito species, daytime resting collections were made by experienced insect collectors in malaria endemic villages of the Dalu Community Health Centre that lie close to the international border with Bangladesh (Figure 1). Mosquitoes adults resting on walls and household articles in human dwellings (indoors) were sampled during early hours (07:00 -09:00 h), and were identified using regional pictorial taxonomical keys to the species level for relative abundance expressed as person hour density. In addition dusk-to-dawn (18:00 - 05:00 h) human landing catches were made in house dwellings (both indoors and outdoors) on the hourly basis to ascertain the biting behaviour of mosquitoes for predilection for human host for which informed consent was taken from the participating volunteers. The mosquitoes collected of both sources were dissected in $0.9 \%$ saline for detection of sporozoite infection in salivary glands. The entomologic inoculation rate (EIR) was calculated as the product of human mosquito landing rate and the proportion of mosquitoes carrying sporozoite infection. The mosquito species thus incriminated were subject to insecticide susceptibility test against DDT (4\%) using standard WHO diagnostic test kit procedures.

\section{Parasitological investigations}

To ascertain the true disease prevalence and parasite species, besides malaria clinic (passive case detection), active fever surveillance was instituted in villages of Dalu Community Health facility for the duration of the study period (May - June 2007). Subjects reporting fever or with history of fever over past few days (clinical cases) were screened for malaria parasite in peripheral finger prick blood-smear using gold standard microscopic technique. Both thick and thin blood-smears stained with Jaswant Singh Bhattacharya (JSB) stain were examined for at least 100 microscopic fields for malaria parasite and species identification before declaring slide negative. Malaria positive cases were administered anti-malarial drugs as per existing national drug policy in force under medical supervision.

\section{Results}

\section{Malaria morbidity and seasonal prevalence}

The available data on malaria-attributable morbidity for the years 2001 - 2009 are presented in Table 1. For each year, the annual blood examination rate (\% of population screened) was $>10 \%$ (the expected rate of fever prevalence in the communities), and considered adequate as per guidelines of the National Vector Borne Disease Control Programme. The overall smear parasite rate (SPR) for the year ranged from $6.4 \%$ in 2002 to $18.8 \%$ in 2009. Similar trends were seen for annual parasite incidences (API) that varied from 12.9 to 68.3 confirmed cases per thousand population/year. Considered for the given year, of total cases confirmed positive, P. falciparum was the predominant infection (>98\%), all others were Plasmodium vivax cases. Malaria cases were recorded in all months, however, with the commencement of the rainy season in April, there was sudden rise in cases beginning May that peaked during May - July (Table 2). These were also the months of high rainfall. Beginning August, there was steady decline in cases but numbers varied with record low during January - April corresponding to dry months/low rainfall. The transmission profile was quite consistent for the years reported but the intensities varied (Figure 2). The cases registered were the highest in 2009 , but $P$. falciparum was the major parasite for all months and years together. Death cases confirmed to be due $P$. falciparum malaria were recorded each year, and varied from 15 in 2001 to 98 in 2007 , and comprised all age-groups of both sexes equally $\left(x^{2}=0.111, P=0.70\right)$. The point prevalence study in Dalu Community Health Centre of the district that lies in close proximity to Bangladesh border revealed that malaria was common ailment in all age groups, and overall parasite rate was 18.2 per cent (207/ 1136) among those reporting fever (Table 3). Of total confirmed positive cases by microscopic examination of blood-smear, P. falciparum constituted $82.6 \%$, and the remaining were $P$. vivax cases.

\section{Entomological observations \\ Mosquito abundance, biting behaviour and infectivity}

Indoor day-resting collections from human dwellings revealed that Anopheles aconitus, Anopheles annularis, Anopheles minimus and Anopheles vagus were prevalent, and their densities varied from 0.05 to 3.18 per person/ hour (Table 4). Of these, An. vagus and An. minimus were common catch constituting bulk of mosquito collections. The majority of An. minimus collected were 
Table 1 Malaria-attributable morbidity in the West Garo hill district of Meghalaya, India*

\begin{tabular}{|c|c|c|c|c|c|c|c|c|}
\hline \multirow[t]{2}{*}{ Year } & \multirow[t]{2}{*}{ Population } & \multicolumn{3}{|c|}{ No. and (\%) of blood-smears } & \multirow{2}{*}{$\begin{array}{c}\% \text { of positive } \\
\text { blood-smears } \\
\text { with } \\
\text { P. falciparum }\end{array}$} & \multirow{2}{*}{$\begin{array}{c}\text { Annual } \\
\text { parasite } \\
\text { incidence } \\
\text { (no. of cases } \\
\text { per } 1000 \\
\text { population) }\end{array}$} & \multirow{2}{*}{$\begin{array}{l}\text { Annual blood examination rate } \\
\text { (\% of population checked) }\end{array}$} & \multirow{2}{*}{$\begin{array}{l}\text { Death } \\
\text { cases }\end{array}$} \\
\hline & & Examined & $\begin{array}{l}\text { Positive for } \\
\text { malaria } \\
\text { parasite } \\
\text { (parasite rate) }\end{array}$ & $\begin{array}{l}\text { Positive for } \\
\text { P. falciparum }\end{array}$ & & & & \\
\hline 2001 & 537346 & 103371 & $8053(7.7)$ & 7971 & 98.9 & 14.9 & 19.2 & 15 \\
\hline 2002 & 550691 & 110371 & $7108(6.4)$ & 7075 & 99.5 & 12.9 & 20.0 & 21 \\
\hline 2003 & 563120 & 87753 & $8910(10.1)$ & 8862 & 99.5 & 15.8 & 15.5 & 25 \\
\hline 2004 & 570492 & 106095 & $9646(9.0)$ & 9568 & 99.1 & 16.9 & 18.5 & 26 \\
\hline 2005 & 574478 & 92743 & $8583(9.2)$ & 8533 & 99.4 & 14.9 & 16.1 & 20 \\
\hline 2006 & 578683 & 131449 & $15203(11.5)$ & 15091 & 99.2 & 26.2 & 22.7 & 36 \\
\hline 2007 & 606062 & 151639 & $21057(13.8)$ & 20914 & 99.3 & 34.7 & 25.0 & 98 \\
\hline 2008 & 630068 & 160675 & $23757(14.7)$ & 23658 & 99.5 & 37.7 & 25.5 & 31 \\
\hline 2009 & 642139 & 232318 & 43879 (18.8) & 43694 & 99.5 & 68.3 & 36.1 & 67 \\
\hline
\end{tabular}

*Source, State Health Directorate of Meghalaya

fully fed, semi-gravid or gravid, of which $39 \%$ were parous. These data were corroborated by indoor and outdoor human landing catches in the dusk-to-dawn mosquito collections (based on one night) in which An. minimus was the most predominant anopheline mosquito species.

The mosquito biting rate per person/night was 4 and 2 indoor and outdoor respectively, whereas only single
Anopheles baimaii (formerly species D of Anopheles dirus) was captured indoors. The peak biting activity of An. minimus occurred during midnight 00 to $02: 00 \mathrm{~h}$. However, Culex species that were most abundant mosquito actively searched human host almost throughout the night, and biting rate were 16 and 11 per person/ night indoor and outdoors respectively. Of total mosquitoes dissected, An. minimus were incriminated by

Table 2 Meteorological data and monthly distribution of malaria cases in the West Garo hill district of Meghalaya, India (Source, State Health Directorate of Meghalaya)

\begin{tabular}{|c|c|c|c|c|c|c|c|c|c|c|}
\hline \multirow{3}{*}{$\begin{array}{l}\text { Month } \\
(2006)\end{array}$} & \multicolumn{5}{|c|}{ Meteorological data } & \multirow{3}{*}{$\begin{array}{l}\text { No. of } \\
\text { blood- } \\
\text { smears } \\
\text { examined }\end{array}$} & \multicolumn{2}{|c|}{ No. (\%) of blood-smears } & \multirow{3}{*}{$\begin{array}{l}\text { Monthly parasite } \\
\text { incidence (no. of cases } \\
\text { per } 1000 \text { population) }\end{array}$} & \multirow{3}{*}{$\begin{array}{l}\text { Death } \\
\text { cases }\end{array}$} \\
\hline & \multirow{2}{*}{$\begin{array}{c}\text { Rain } \\
\text { fall } \\
(\mathrm{mm})\end{array}$} & \multirow{2}{*}{$\begin{array}{l}\text { No. of } \\
\text { rainy } \\
\text { days }\end{array}$} & \multicolumn{2}{|c|}{$\begin{array}{c}\text { Temperature } \\
\left({ }^{\circ} \mathrm{C}\right)\end{array}$} & \multirow{2}{*}{$\begin{array}{c}\text { Average } \\
\text { Relative } \\
\text { Humidity } \\
\text { (\%RH) }\end{array}$} & & \multirow[t]{2}{*}{$\begin{array}{l}\text { Positive for } \\
\text { P. falciparum }\end{array}$} & \multirow[t]{2}{*}{$\begin{array}{l}\text { Positive for } \\
\text { P. vivax }\end{array}$} & & \\
\hline & & & Max & Min & & & & & & \\
\hline January & 0 & 0 & 28.0 & 10.0 & 65 & 3891 & $256(6.6)$ & $01(0.03)$ & 0.44 & 0 \\
\hline February & 26.8 & 3 & 35.1 & 20.2 & 65 & 4586 & $272(5.9)$ & $0(0)$ & 0.47 & 0 \\
\hline March & 12.2 & 2 & 35.0 & 20.0 & 58 & 6097 & $452(7.4)$ & $08(0.1)$ & 0.79 & 0 \\
\hline April & 204.6 & 9 & 27.7 & 25.0 & 67 & 5324 & $420(7.9)$ & $10(0.2)$ & 0.74 & 3 \\
\hline$\overline{\text { May }}$ & 708.2 & 19 & 27.4 & 24.0 & 72 & 10108 & $1207(11.9)$ & $23(0.2)$ & 2.12 & 8 \\
\hline June & 442.8 & 20 & 27.0 & 24.4 & 76 & 19484 & $2192(11.3)$ & $07(0.04)$ & 3.80 & 3 \\
\hline July & 463.2 & 24 & 28.2 & 27.0 & 73 & 21329 & $2957(13.9)$ & $12(0.06)$ & 5.13 & 5 \\
\hline August & 246.2 & 20 & 29.2 & 26.0 & 74 & 11623 & $1500(12.9)$ & $03(0.03)$ & 2.59 & 2 \\
\hline September & 318.4 & 19 & 28.2 & 25.1 & 75 & 9913 & $886(8.9)$ & $0(0)$ & 1.53 & 0 \\
\hline October & 189.8 & 10 & 29.0 & 25.9 & 68 & 15867 & $1929(12.2)$ & $10(0.06)$ & 3.35 & 4 \\
\hline November & 0 & 0 & 26.9 & 24.1 & 71 & 12107 & $1230(10.2)$ & $08(0.07)$ & 2.14 & 7 \\
\hline December & 0 & 0 & 24.9 & 21.8 & 74 & 11120 & $1790(16.1)$ & $30(0.3)$ & 3.14 & 4 \\
\hline
\end{tabular}




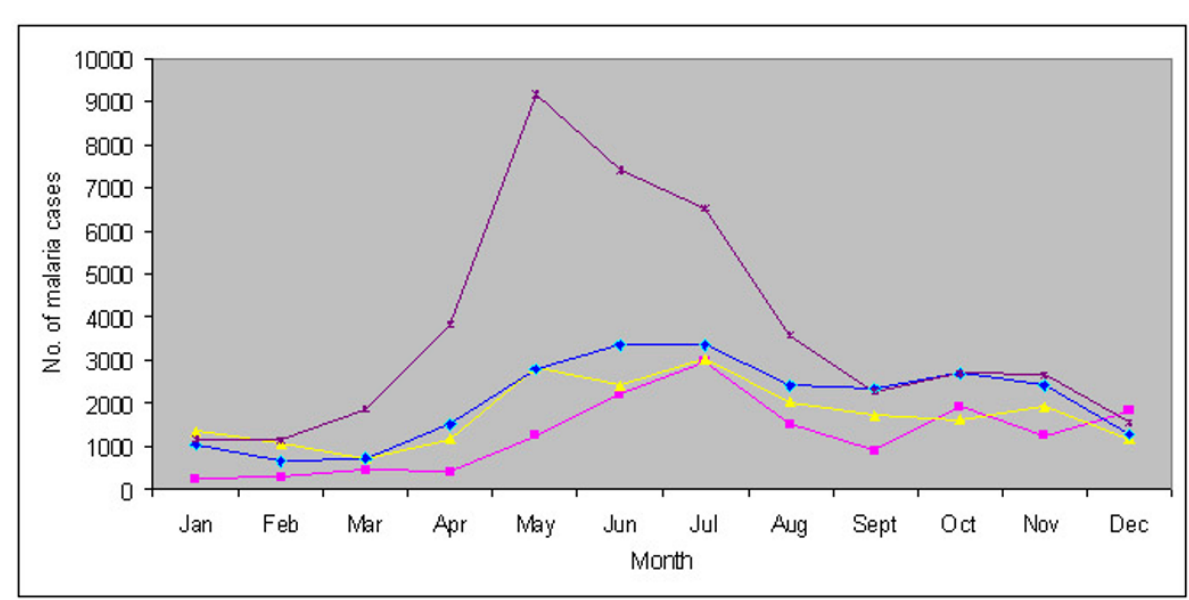

Figure 2 Monthly distribution of malaria cases in the West Garo hill district of Meghalaya in 2006 (pink square), 2007 (yellow triangle), 2008 (blue spade) and 2009 (violet cross).

detection of sporozoites in salivary glands, and infection rate was $2.27 \%(2 / 88)$; all other mosquito species were sporozoite negative. Given the data on mosquito biting rate and sporozoite infectivity, the entomologic inoculation rate (a product of sporozoite infection rate $\times$ the human mosquito-biting rate) for both indoor and outdoor was 0.090 and 0.045 respectively. The locally collected adult mosquito populations of An. minimus when subjected to DDT (4\%) susceptibility test (the residual insecticide in use for vector control) resulted in 100\% mortality post $24 \mathrm{~h}$ exposure, and was observed to be consistent for the two replicates of 15 mosquitoes each, thus ascertained to be fully susceptible at given diagnostic concentration.

\section{Discussion}

In north-east India, disease distribution is geographically restricted but remains entrenched in population groups living in poverty particularly in foothill villages/interborder areas [4]. The Garo hill districts in Meghalaya persistently contributed most cases and malaria-attributable deaths, and deserve priority for strengthening interventions. The problem is complex along international borders of the northeast due to poor inter-country coordinated vector control interventions, illiteracy, difficult terrain and poor access to healthcare services [5]. The highest death toll of 98 in 2007 was ascribed to focal disease outbreaks along Indo-Bangla border, and every single death was confirmed to be due to $P$. falciparum malaria that is widely prevalent and believed to be multi-drug resistant [6]. Most death cases that were preventable occurred of complications arising due to late reporting and consequent delayed treatment (source, state health directorate). The disease burden due to malaria is estimated to be much higher for many clinical and death cases for which no blood-smear report was available were excluded from the surveillance data [7]. From the point prevalence study, it was revealing that the relative abundance of $P$. falciparum cases was lower (82\%) than what is being reported under state surveillance accounting for $99 \%$ of the reported cases (Table 1,3). Seemingly for want of laboratory expertise, many $P$. vivax cases perhaps were misdiagnosed as $P$. falciparum by state technicians amounting to unwarranted use of anti-malarials. The fact that mixed infections of both the prevalent parasite species were not observed underlines that the transmission intensity is low-to-moderate. The unusual high rise in reported cases, however, beginning 2007 (formerly underreported) could be ascribed to induction of rapid

Table 3 Prevalence of malaria in Dalu Community Health Centre, West Garo hill district of Meghalaya, India*

\begin{tabular}{cccc}
\hline $\begin{array}{c}\text { Age group in } \\
\text { years }\end{array}$ & $\begin{array}{c}\text { No. of blood- smears } \\
\text { examined }\end{array}$ & $\begin{array}{c}\text { No. \& (\%) of smears positive for } \\
\text { malaria }\end{array}$ & $\begin{array}{c}\text { No. \& (\%) of malaria cases positive for } \\
\text { P. falciparum }\end{array}$ \\
\hline $1-4$ & 283 & $58(20.5)$ & $46(79.3)$ \\
\hline $5-8$ & 245 & $51(20.8)$ & $42(82.3)$ \\
\hline $9-14$ & 205 & $53(25.8)$ & $44(83.0)$ \\
\hline$\geq 15$ & 403 & $45(11.2)$ & $39(86.7)$ \\
\hline Total & $\mathbf{1 1 3 6}$ & $\mathbf{2 0 7 ( 1 8 . 2 )}$ & $\mathbf{1 7 1}(\mathbf{8 2 . 6 )}$ \\
\hline
\end{tabular}

*Study period, May - June 2007 
Table 4 Relative abundance and dissection records of anopheline mosquito species from human dwellings (indoor) in malaria endemic villages of Dalu Community Health Centre of the West Garo hill district of Meghalaya, India*

\begin{tabular}{|c|c|c|c|c|c|c|c|c|}
\hline \multirow[t]{2}{*}{ Mosquito species } & \multirow{2}{*}{$\begin{array}{l}\text { No. mosquitoes } \\
\text { collected }\end{array}$} & \multicolumn{4}{|c|}{ Abdominal condition** } & \multirow{2}{*}{$\begin{array}{l}\text { Density per person hour } \\
\text { (person hours }=39 \text { ) }\end{array}$} & \multicolumn{2}{|c|}{ Vector incrimination } \\
\hline & & UF & $\mathrm{FF}$ & SG & G & & No. dissected & Sporozoite Infection rate (\%) \\
\hline An. aconitus & 02 & 2 & 0 & 0 & 0 & 0.05 & 2 & $0(0)$ \\
\hline An. annularis & 02 & 0 & 0 & 0 & 2 & 0.05 & 02 & $0(0)$ \\
\hline An. minimus & 124 & 4 & 33 & 48 & 39 & 3.18 & 88 & $2(2.27)$ \\
\hline An. vagus ${ }^{* * *}$ & 122 & - & - & - & - & 3.13 & 77 & $0(0)$ \\
\hline
\end{tabular}

*Study period: May - June 2007

** UF = Unfed, FF = Fully fed, SG = Semi gravid, G = Gravid

*** Abdominal condition not scored due to zoophilic nature/lesser significance

diagnostic kits (RDKs) for on-the-spot diagnosis by female Accredited Social Health Activists (ASHA) workers in door-to-door surveillance. From the presented data, it was evident that disease transmission is not only perennial but persistent calling for concerted efforts in devising appropriate interventions in place for much needed transmission reduction. It is widely believed that these pockets serve as reservoirs of drug-resistant strains that are fast evolving due to mixing of strains owing to population movement across borders with an opportunity to spread through anthropophilic mosquito vectors that are widely prevalent [8].

The present study clearly established that An. minimus is the major vector in Garo hills based on detection of sporozoite infection in the salivary glands. The morphologically identified populations of this species complex in north-east have earlier been characterized to be An. minimus based on molecular data $[9,10]$. Even though $A n$. minimus mosquitoes were highly susceptible to DDT, but transmission continued uninterrupted largely due to poor quality spray coverages, and high refusal rates by the communities making it inadequate intervention. The local agricultural practice of shifting cultivation made it difficult for effective surveillance during the period (May - September) which somehow coincided with the high transmission period. This practice presumably resulted in parasite reservoir for many individuals remained untreated rendering them asymptomatic carriers. In north-eastern states, 10-30 per cent of malaria endemic communities are reported to be asymptomatic cases, which are unlikely to seek treatment [11]. Apparently, both the inadequate interventions against vector mosquito populations and parasite reservoir in the communities facilitated the year-round transmission observed. In the adjoining state of Assam with similar transmission dynamics, risk factor is assessed to be much greater in foothill/inter-border villages for infective mosquito bites calling far greater allocation of resources for effective control [12]. Among other documented vector species in the northeast, of
An. dirus species complex, the role An. baimaii (populations of which have been characterized by molecular evidence) could not be clearly substantiated in this locality [13]. Seemingly, its numbers are dwindling due to deforestation at the expense of population explosion and increased acreage under paddy cultivation. Given the entomologic inoculation rates, the transmission intensity is estimated to be low-to-moderate. However, there is every risk of replacement of $P$. vivax with that of drug-resistant $P$. falciparum as that has been reported in central India in similar physiographic locales [14].

It is satisfying that the given the present scenario, interventions are currently being strengthened by increased allocation under Global Fund to fight against AIDS, Tuberculosis and Malaria (GFATM) by additional tools, i.e., the impregnation of community-owned mosquito nets, provision of mosquito net especially for below poverty line families, wide access to effective chemotherapy using artemisinin-based combination therapy $(\mathrm{ACT})$, improved disease surveillance and diagnosis using RDKs, induction of ASHA female workers for early diagnosis, increased involvement of Non Governmental Organizations and civic societies. Aiming at containment of drug-resistant malaria prevalent in Garo hills, we strongly advocate sustained interventions ensuring supply of ACT which should be enforced for treatment of every single case of $P$. falciparum. The therapeutic response to ACT presently in force (artesunate + sulphadoxine-pyrimethamine) has been assessed to be adequate (unpublished observations), and holds good promise in rolling back malaria, and saving lives [15-17]. To avert the malaria disaster, strengthening of healthcare services in the periphery where there is need most for better case management, enhanced DDT spray coverage by making it a community-based activity, increased awareness on disease prevention, and greater political commitment for organized control operations along border/high-risk areas are strongly recommended. It is believed that in areas with low-to-moderate transmission, rolling back malaria is possible with all these 
combined measures that would help restore confidence in the communities and all round socio-economic development $[18,19]$.

\section{Conclusion}

The Garo hills of Meghalaya that share an international border with Bangladesh are co-endemic for $P$. vivax and $P$. falciparum malaria. Transmission of the causative parasites is perennial and persistent with seasonal peak during May - July corresponding to months of high rainfall. Entomological collections revealed that $A n$. minimus was the predominant mosquito species that was incriminated by detection of sporozoites in salivary glands (infection rate 2.27\%), and ascertained to be fully susceptible to DDT. For the control of malaria, along with greater political commitment for organized vector control operations along border/high-risk areas, improved diagnosis and sustained supply of artemisininbased combination therapy are advocated for treatment of every single case of $P$. falciparum averting spread of drug-resistant malaria and impending disease outbreaks.

\section{Acknowledgements}

We are thankful to the Incharge, Dalu Community Health Centre for logistics support, and the local communities for active cooperation. The study was sponsored by the Indian Council of Medical Research under North-East Fund assistance initiative. Technical assistance of the project staffs is gratefully acknowledged. Meteorological data were provided by the Agricultural Experimental Station, Tura, Meghalaya.

\section{Author details}

${ }^{1}$ National Institute of Malaria Research (Field Station), Chachal, Guwahati 781 022, Assam, India. ${ }^{2}$ National Vector Borne Disease Control Programme, District Malaria Officer, Tura - 794 001, Meghalaya, India. ${ }^{3}$ National Institute of Malaria Research (ICMR), Dwarka, Delhi - 110 077, India.

\section{Authors' contributions}

VD: Collected and analyzed the data, and developed the first draft of the manuscript. BMS: Epidemiological data collection and compilation, data analysis (in part), and local study coordination. APD: Study planning and coordination. All authors read and approved the final version of the manuscript.

\section{Competing interests}

The authors declare that they have no competing interests.

Received: 31 March 2010 Accepted: 22 September 2010

Published: 22 September 2010

\section{References}

1. Dev V, Bhattacharyya PC, Talukdar R: Transmission of malaria and its control in the Northeastern Region of India. J Assoc Physicians India 2003, 51:1073-1076.

2. Dev V: Integrated disease vector control of malaria: a success story based in Assam, northeastern India. ICMR Bulletin 2009, 39:21-28.

3. Ministry of Health and Family Welfare, Government of India: Directorate of National Vector Borne Disease Control Programme. [http://www.nvbdcp. gov.in], (Accessed 12 October 2008).

4. Dev V, Dash AP, Khound K: High-risk areas of malaria and prioritizing interventions in Assam. Curr Sci 2006, 90:32-36.

5. Dash AP, Valecha N, Anvikar AR, Kumar A: Malaria in India: Challenges and opportunities. J Biosci 2008, 33:583-592.
6. Mohapatra PK, Namchoom NS, Prakash A, Bhattacharya DR, Goswami BK, Mahanta J: Therapeutic efficacy of anti-malarials in Plasmodium falciparum malaria in an Indo-Myanmar border area of Arunachal Pradesh. Indian J Med Res 2003, 118:71-76.

7. WHO: World Malaria Report 2008. Geneva: World Health Organization 2008 [http://malaria.who.int/wmr2008/], (Accessed 12 October 2008).

8. Joshi H, Valecha N, Verma A, Kaul A, Mallick PK, Shalini S, Prajapati SK, Sharma SK, Dev V, Biswas S, Nanda N, Malhotra MS, Subbarao SK, Dash AP: Genetic structure of Plasmodium falciparum field isolates in eastern and north-eastern India. Malar J 2007, 6:60.

9. Singh OP, Nanda N, Dev V, Bali P, Sohail M, Mehrunnisa A, Adak T, Dash AP Moelcular evidence of misidentification of Anopheles minimus as Anopheles fluviatilis in Assam (India). Acta Trop 2010, 113:241-244.

10. Prakash A, Walton C, Bhattacharyya DR, Loughlin SO, Mohapatra PK, Mahanta J: Molecular characterization and species identification of the Anopheles dirus and An. minimus complexes in north-east India using rDNA ITS-2. Acta Trop 2006, 100:156-161.

11. Dev V, Phookan S, Sharma VP, Dash AP, Anand SP: Malaria parasite burden and treatment seeking behavior in ethnic communities of Assam, Northeastern India. J Infection 2006, 52:131-139.

12. Dev V, Phookan S, Sharma VP, Anand SP: Physiographic and entomologic risk factors of malaria in Assam, India. Am J Trop Med Hyg 2004, 71:451-456.

13. Loughlin SM, Okabayashi T, Honda M, Kitazoe Y, Kishino H, Somboon P, Sochantha T, Nambanya S, Saikia PK, Dev V, Walton C: Complex population history of two Anopheles dirus mosquito species in Southeast Asia suggest the influence of Pleistocene climate change rather that humanmediated effects. J Evol Biol 2008, 21:1555-1569.

14. Singh N, Nagpal AC, Saxena A, Singh MP: Changing scenario of malaria in central India: the replacement of Plasmodium vivax by $P$. falciparum (1986-2000). Trop Med Int Health 2004, 9:364-371.

15. Morel CM, Lauer JA, Evans DB: Cost effectiveness analysis of strategies to combat malaria in developing countries. BMJ 2005, 331:1299-1305.

16. White $\mathrm{NJ}$ : The role of anti-malarial drugs in eliminating malaria. Malar $J$ 2008, 7(Suppl 1):S8.

17. Whitty CJM, Chandler C, Ansah E, Leslie T, Staedke SG: Deployment of ACT antimalarials for treatment of malaria: challenges and opportunities. Malar J 2008, 7(Suppl 1):S7.

18. Beier JC, Keating J, Githure Jl, Macdonald MB, Impoinvil DE, Novak RJ: Integrated vector management for malaria control. Malar J 2008, 7(Suppl 1):S4.

19. Narain JP: Malaria in the South-East Asia Region: Myth \& the reality. Indian J Med Res 2008, 128:1-3.

doi:10.1186/1475-2875-9-263

Cite this article as: Dev et al:: Persistent transmission of malaria in Garo

hills of Meghalaya bordering Bangladesh, north-east India. Malaria Journal 2010 9:263.

\section{Submit your next manuscript to BioMed Central and take full advantage of:}

- Convenient online submission

- Thorough peer review

- No space constraints or color figure charges

- Immediate publication on acceptance

- Inclusion in PubMed, CAS, Scopus and Google Scholar

- Research which is freely available for redistribution 